\title{
Registered report: Kinase-dead BRAF and oncogenic RAS cooperate to drive tumor progression through CRAF
}

\section{Ajay Bhargava', Madan Anant', Hildegard Mack², Reproducibility Project: Cancer Biology*}

\author{
${ }^{1}$ Shakti BioResearch LLC, Woodbridge, United States; ${ }^{2}$ University of California, San \\ Francisco, San Francisco, United States
}

REPRODUCIBILITY CAROJECT CANCER BIOLOGY

\begin{abstract}
*For correspondence: nicole@ scienceexchange.com
\end{abstract}

Group author details:

Reproducibility Project: Cancer Biology See page 26

Competing interest: See page 26

Funding: See page 27

Received: 02 October 2015 Accepted: 25 January 2016 Published: 17 February 2016

Reviewing editor: Roger Davis, Howard Hughes Medical Institute \& University of Massachusetts Medical School, United States

(c) Copyright Bhargava et al. This article is distributed under the terms of the Creative Commons Attribution License, which permits unrestricted use and redistribution provided that the original author and source are credited.
Abstract The Reproducibility Project: Cancer Biology seeks to address growing concerns about reproducibility in scientific research by conducting replications of selected experiments from a number of high-profile papers in the field of cancer biology. The papers, which were published between 2010 and 2012, were selected on the basis of citations and Altmetric scores (Errington et al., 2014). This Registered Report describes the proposed replication plan of key experiments from "Kinase-dead BRAF and oncogenic RAS cooperate to drive tumor progression through CRAF" by Heidorn and colleagues, published in Cell in 2010 (Heidorn et al., 2010). The experiments to be replicated are those reported in Figures 1A, 1B, 3A, 3B, and 4D. Heidorn and colleagues report that paradoxical activation of the RAF-RAS-MEK-ERK pathway by BRAF inhibitors when applied to BRAFWT cells is a result of BRAF/CRAF heterodimer formation upon inactivation of BRAF kinase activity, and occurs only in the context of active RAS. The Reproducibility Project: Cancer Biology is a collaboration between the Center for Open Science and Science Exchange, and the results of the replications will be published by eLife.

DOI: 10.7554/eLife.11999.001

\section{Introduction}

The RAS-RAF-MEK-ERK signaling pathway is routinely disregulated in many forms of cancer. Activating mutations in BRAF are found in almost half of all melanomas, and of these mutations, almost $90 \%$ involve a valine to glutamic acid transition at position 600 (BRAF ${ }^{\mathrm{V} 600 \mathrm{E}}$ ) (Solit and Rosen 2014). The therapeutic effect of drugs that target this form of BRAF have proved less efficacious than expected, due to an unexpected effect in cells that are BRAF ${ }^{\mathrm{WT}}$; in these cells, drugs that target BRAF paradoxically activate rather than repress downstream signaling (Hall-Jackson et al., 1999a; Hall-Jackson et al., 1999b). In their 2010 paper, Heidorn and colleagues examined the mechanism of action behind this paradoxical activation of MEK/ERK signaling. Heidorn and colleagues first observed that paradoxical activation occurred only in the context of BRAFWT and activated RAS, an observation confirmed by two other groups (Hatzivassiliou et al., 2010; Poulikakos et al., 2010). Dissecting the mechanism, they reported that the formation of BRAF/CRAF heterodimers was necessary for pathway activation, and formation of those heterodimers required active RAS signaling.

In Figure 1A, Heidorn and colleagues examined pathway activation in response to a range of drugs. The inhibitors, sorafenib, which targets and represses both BRAF and CRAF, PLX4720, which is highly selective for and inhibits the activity of BRAF ${ }^{\mathrm{V} 600 \mathrm{E}}$. 885-A, which specifically targets and inhibits BRAF, and the MEK inhibitor PC184352 were examined. As expected, all four drugs blocked MEK/ERK activation in BRAF ${ }^{\mathrm{V} 600 E}$ A375 cells. However, in cells with active RAS, such as D04 cells (BRAF $^{\mathrm{WT}} / \mathrm{NRAS}^{\mathrm{Q} 61 \mathrm{~L}}$ ), MEK/ERK signaling was not repressed by PLX4720 or 885-A. This paradoxical activation in BRAF ${ }^{\mathrm{WT}}$ cells was also observed by several other groups (Carnahan et al., 2010; 
Joseph et al., 2010; Lee et al., 2010; Kaplan et al., 2011). This experiment will be replicated in Protocol 1.

Previous work had shown that activated RAS in melanoma signals through CRAF, while normal signaling in healthy melanocytes is accomplished through BRAF (Dumaz et al., 2006). To determine if CRAF was required for paradoxical pathway activation, Heidorn and colleagues treated D04 cells with siRNAs targeting NRAS and CRAF. Knockdown of either NRAS or CRAF abrogated activation of MEK/ERK by 885-A, as seen in Figure 1B. This experiment will be replicated in Protocol 2. The necessity of CRAF also explains the lack of activation upon treatment with sorafenib observed in Figure 1A; since sorafenib inhibits both BRAF and CRAF, it does not result in pathway activation.

Since activated RAS is known to drive heterodimerization of BRAF and CRAF (Weber et al., 2001), Heidorn and colleagues also tested if drug binding drove heterodimerization of BRAF and CRAF, and if this heterodimerization was dependent on active RAS signaling. In Figure 3A, they

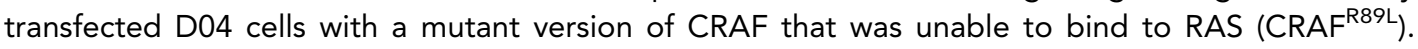
Immunoprecipitation experiments showed that while CRAF ${ }^{\mathrm{WT}}$ was able to bind to BRAF in the presence of activated RAS, CRAF ${ }^{R 9 L}$ was unable to bind to BRAF. This key experiment will be replicated in Protocol 3.

The authors showed that BRAF binds to CRAF but only in the presence of WT RAS, not oncogenic RAS. In Figure 3B, myc-tagged BRAF or myc-tagged mutant BRAF ( ${ }^{\mathrm{R} 188 \mathrm{~L}} \mathrm{BRAF}$ ) were transfected into D04 cells and treated with either DMSO(-) or $885-\mathrm{A}(+)$. The authors show that mutant of BRAF ( ${ }^{\mathrm{R} 188 \mathrm{~L}} \mathrm{BRAF}$ ) does not bind to CRAF even in the presence of 885-A, which induces RAS activity.

After confirming that drug binding to BRAF drove BRAF binding to CRAF, Heidorn and colleagues tested a kinase dead version of BRAF (BRAF ${ }^{\mathrm{D} 94 \mathrm{~A}}$ ) (Figure 4D). Interestingly, this version of BRAF still bound to CRAF, indicating that it is not drug binding per se, but inhibition of BRAF activity, that drives BRAF binding to CRAF and paradoxical activation of MEK/ERK. This key experiment will be replicated in Protocol 4.

Packer and colleagues extended the work of Heidorn and colleagues to examine if other more broadly targeted tyrosine kinase inhibitors were also able to paradoxically activate the RAS-RAF pathway. They observed paradoxical pathway activation in D04 cells after treatment with imatinib, nilotinib, dasatinib, and the BRAF inhibitor SB590885. As in Heidorn et al., paradoxical activation only occurred in cells with BRAFWT and required active RAS, as knockdown of NRAS abrogated the effect. Interestingly, while Heidorn and colleagues reported that knockdown of CRAF alone was able to block paradoxical activation, Packer and colleagues reported that only combined knockdown of BRAF and CRAF was able to block paradoxical activation (Packer et al., 2011). Work by Rebocho and colleagues and by Kaplan and colleagues aligned with Heidorn's findings that silencing of CRAF alone was able to abrogate paradoxical activation (Aplin et al., 2011; Rebocho and Marais 2012). Packer and colleagues also reported that BRAF/CRAF heterodimerization was dependent upon RAS by demonstrating that CRAF ${ }^{R 81}$ was unable to form heterodimers with BRAF (Packer et al., 2011).

Activation of NRAS signaling appears to be a key step in acquired drug resistance, supporting the hypothesis that paradoxical activation can only occur in the context of active RAS signaling. Su and colleagues derived a drug-resistant $\mathrm{BRAF}^{\mathrm{V} 600 \mathrm{E}}$ melanoma cell line by growing $\mathrm{A} 375$ cells in the presence of vemurafenib (PLX4032, a BRAF ${ }^{\mathrm{V} 600 E}$ inhibitor). Interestingly, drug resistance was dependent on expression of CRAF, and the resistant lines that emerged had acquired an activating mutation in KRAS (Su et al., 2012). Nazarian and colleagues also observed the acquisition of activating mutations in NRAS when they derived PLX4032-resistant cell lines (Nazarian et al., 2010). Lidsky and colleagues also showed that increased levels of NRAS were key to vemurafenib resistance, although they did not observe any activating mutations in their resistant cell lines (Lidsky et al., 2014).

\section{Materials and methods}

Unless otherwise noted, all protocol information was derived from the original paper, references from the original paper, or information obtained directly from the authors. An asterisk (*) indicates data or information provided by the Reproducibility Project: Cancer Biology core team. A hashtag (\#) indicates information provided by the replicating lab. 


\section{Protocol 1: Treatment of BRAF mutant cells with various RAF inhibitors and assessment of activation of ERK}

This protocol describes how to treat NRAS mutant D04 cells and NRAS wild-type cells also carrying the BRAF ${ }^{\mathrm{V} 600 \mathrm{E}}$ mutation with various BRAF inhibitors and assess ERK phosphorylation by Western blot, as reported in Figure $1 \mathrm{~A}$.

\section{Sampling}

- The experiment will be performed independently at least three times for a final power of at least $80 \%$. The original data is qualitative, thus to determine an appropriate number of replicates to initially perform, sample sizes based on a range of potential variance was determined.

- See Power calculations for details.

- Each experiment consists of eight cohorts:

- Cohort 1: D04 cells treated with DMSO

- Cohort 2: D04 cells treated with PD184352

- Cohort 3: D04 cells treated with sorafenib

- Cohort 4: D04 cells treated with SB590885

- Cohort 5: A375 cells treated with DMSO

- Cohort 6: A375 cells treated with PD184352

- Cohort 7: A375 cells treated with sorafenib

- Cohort 8: A375 cells treated with SB590885

- Each cohort will be probed for ppERK and ERK2 by Western blot.

Materials and reagents

\begin{tabular}{|c|c|c|c|c|}
\hline Reagent & Type & Manufacturer & Catalog \# & Comments \\
\hline D04 cells & Cells & \multicolumn{3}{|c|}{$\begin{array}{l}\text { Provided by Chris Schmidt, Queensland Institute of } \\
\text { Medical Research (QIMR) Berghofer, Australia }\end{array}$} \\
\hline A375 cells & Cells & \multicolumn{3}{|l|}{ ATCC } \\
\hline RPMI & Cell culture media & Life Technologies & \multicolumn{2}{|l|}{ 21875-034 } \\
\hline DMEM & Cell culture media & Life Technologies & \multicolumn{2}{|l|}{$41966-029$} \\
\hline FBS & Reagent & Life Technologies & \multicolumn{2}{|l|}{10270106} \\
\hline 35-mm culture plates & Material & Corning & CLS430165 & Original not specified \\
\hline Sorafenib & Drug & Selleckchem & \multicolumn{2}{|l|}{ S7397 } \\
\hline PD184352 & Drug & Selleckchem & \multicolumn{2}{|l|}{$\mathrm{S} 1020$} \\
\hline SB590885 & Drug & Selleckchem & $\mathrm{S} 2220$ & *Replaces Plexxion 885-A \\
\hline DMSO & Reagent & Fisher Scientific & D128-500 & Original not specified \\
\hline PBS & Reagent & Gibco & $10010-023$ & Original not specified \\
\hline Tris- $\mathrm{HCl}$ & Chemical & \multirow{6}{*}{\multicolumn{3}{|c|}{$\begin{array}{l}\text { Specific brand information will be left up } \\
\text { to the discretion of the replicating lab and recorded later }\end{array}$}} \\
\hline $\mathrm{NaCl}$ & Chemical & & & \\
\hline Igepal & Chemical & & & \\
\hline $\mathrm{Na}_{3} \mathrm{VO}_{4}$ & Chemical & & & \\
\hline $\mathrm{NaF}$ & Chemical & & & \\
\hline Leupeptin & Chemical & & & \\
\hline Bradford Assay & Detection Assay & Bio-Rad Laboratories & 5000001 & Original not specified \\
\hline NuPAGE Sample buffer & Buffer & Invitrogen & NP0007 & Original not specified \\
\hline SDS-Page gel (4-12\%) & Western blot reagent & Invitrogen & NP0322BOX & Original not specified \\
\hline Nitrocellulose membrane (iBlot) & Western blot reagent & Invitrogen & IB301002 & Original not specified \\
\hline Ponceau stain & Western blot reagent & Sigma-Aldrich & P7170-1L & Original not specified \\
\hline Tris & Chemical & Sigma-Aldrich & T6066 & Original not specified \\
\hline
\end{tabular}

Continued on next page 
Continued

\begin{tabular}{lllll} 
Reagent & Type & Manufacturer & Catalog \# & Comments \\
\hline Tween-20 & Chemical & Sigma-Aldrich & P1379 & Original not specified \\
\hline Mouse $\alpha$-ppERK1/2 & Antibody & Cell Signaling Technology & 9106 & Replaces Sigma M8159 \\
\hline Rabbit $\alpha$-ERK1/2 & Antibody & Cell Signaling Technology & 9102 & Replaces Santa Cruz Bio sc-154 \\
\hline HRP-conjugated secondary antibody & Western blot reagent & Bio-Rad & $170-5047$ & Original not specified \\
\hline ECL Detection Kit & Western blot reagent & Invitrogen & 32132 & Original not specified \\
\hline
\end{tabular}

*Suggested as suitable replacement by original authors by personal communication

\section{Procedure}

- All cells will be sent for mycoplasma testing and STR profiling.

- D04 cells are maintained in RPMI supplemented with $10 \%$ FBS.

- A375 cells are maintained in DMEM supplemented with $10 \%$ FBS.

- All cell lines are maintained at $37^{\circ} \mathrm{C}$ with $10 \% \mathrm{CO}_{2}$.

- Sorafenib, PD184352, and SB590885 are dissolved in DMSO.

1. Seed $1.0-2 \times 10^{5}$ cells per well of a six-well tissue culture plate (cells should be $80 \%$ confluent at the time of drug treatment).

2. Treat cells with drug or equivalent volume vehicle (DMSO, <0.2\%) for 4 .

1. $10 \mu \mathrm{M}$ Sorafenib

2. $1 \mu \mathrm{M}$ SB590885

3. $1 \mu \mathrm{M}$ PD184352

3. Lyse cells

1. Place cells on ice and aspirate media.

2. Wash three times with ice-cold PBS.

3. Scrape cells into $50-200 \mu$ l of Nonidet P40 extraction buffer.

1. NP40 extraction buffer: $50 \mathrm{mM}$ Tris- $\mathrm{HCl}, \mathrm{pH} 7.5,150 \mathrm{mM} \mathrm{NaCl}, 0.55$ (v/v) lgepal, 5 $\mathrm{mM} \mathrm{NaF}, 0.2 \mathrm{mM} \mathrm{Na}_{3} \mathrm{VO}_{4}, 5 \mu \mathrm{g} / \mathrm{ml}$ leupeptin

2. Incubate on ice for $5 \mathrm{~min}$.

4. Shear cells by passing through a pipette tip several times.

5. Centrifuge samples at $20,000 \times g$ for $5 \mathrm{~min}$ at $4^{\circ} \mathrm{C}$.

6. Harvest the soluble fraction for further analysis.

7. "Quantify protein concentration using a Bradford assay.

4. Analyze cell lysates by Western blot for phospho-ERK and total ERK.

1. Load equal amounts of all samples (30-50 $\mu$ g; approximately half of the lysate) mixed with $4 \mathrm{x}$ sample buffer and boiled at $90^{\circ} \mathrm{C}$ for $5-10 \mathrm{~min}$ on a ${ }^{\#} 4-12 \%$ SDS-Page gel.

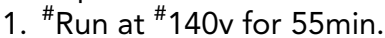

2. " Transfer to a nitrocellulose membrane at $250 \mathrm{~mA}$ for $1 \mathrm{hr}$

1. ${ }^{\star}$ Confirm protein transfer by Ponceau staining and image membrane.

3. "Block membrane in 5\% non-fat dried milk in TBST $(20 \mathrm{mM}$ Tris $\mathrm{pH} 7.5,136 \mathrm{mM} \mathrm{NaCl}$, $0.1 \%$ Tween-20).

4. Incubate membrane at $4^{\circ} \mathrm{C}$ overnight with antibodies against:

1. Mouse $\alpha$-ppERK1/2: 1:1000 dilution

2. " Rabbit $\alpha$-ERK1/2: 1:1000 dilution

5. " Incubate with HRP-conjugated secondary antibody diluted 1:10,000 in 1X TBS for $1 \mathrm{hr}$ at room temperature.

1. Rinse the membrane twice with TBST.

2. Wash the membrane twice with TBST for 5 min each.

6. "Visualize bands with ECL detection kit according to manufacturer's protocol.

1. Quantify band intensity.

2. Normalize pERK to ERK $1 / 2$ for each condition.

7. Repeat independently two additional times. 


\section{Deliverables}

- Data to be collected:

- Protein quantification results from Bradford assay.

- Images of Ponceau stained membranes.

- Raw images of whole gels with ladders included (as reported in Figure 1A).

- Densitometric quantification of all bands.

\section{Confirmatory analysis plan}

- Statistical Analysis of the Replication Data:

Note: At the time of analysis, we will perform the Shapiro-Wilk test and generate a quantile-quantile plot to assess the normality of the data. We will also perform Levene's test to assess homoscedasticity. If the data appears skewed, we will perform a transformation in order to proceed with the proposed statistical analysis. If this is not possible, we will perform the equivalent non-parametric test listed.

- Two-way ANOVA on normalized pERK values (to ERK1/2) in A375 or D04 cells treated with PD184352, sorafenib, SB590885, or vehicle (DMSO) with the following planned contrasts with the Bonferroni correction:

- Normalized pERK band intensity in A375 cells:

- Vehicle treatment vs. all three drug treatments (PD184352, sorafenib, and SB590885)

- Normalized pERK band intensity in D04 cells:

- Vehicle treatment vs. PD184352 and SB590885 treatments

- Vehicle treatment vs. sorafenib treatment

- Meta-analysis of original and replication attempt effect sizes:

- The replication data (mean and 95\% confidence interval) will be plotted with the original quantified data value displayed as a single point on the same plot for comparison.

Known differences from the original study

The replication attempt will use D04 and A375 cells and will exclude MM415, MM485, and WM852 cells. It will also exclude the drug PLX4720 and will replace 885-A with its analogue SB590885. The original authors suggest they have found similar results with this analogue (personal communication with Dr. Dhomen). All known differences, if any, are listed in the 'Materials and reagents' section above with the originally used item listed in the comments section. The comments section also lists if the source of original item was not specified. All differences have the same capabilities as the original and are not expected to alter the experimental design.

\section{Provisions for quality control}

All data obtained from the experiment - raw data, data analysis, control data, and quality control data - will be made publicly available, either in the published manuscript or as an open access dataset available on the Open Science Framework (https://osf.io/b1aw6/). Cells will be sent for mycoplasma testing confirming lack of contamination and STR profiling confirming cell line authenticity. The transfer efficiency during the Western blot procedure will be monitored by Ponceau staining.

\section{Protocol 2: Treatment of NRAS or CRAF silenced D04 cells with SB590885 and assessment of MEK and ERK phosphorylation}

This protocol describes treatment of D04 cells transfected with siRNAs targeting NRAS or CRAF with SB590885 and assessment of those cells for activation of MEK and ERK by Western blot, as reported in Figure 1B.

\section{Sampling}

- The experiment will be performed independently at least four times for a final power of at least $80 \%$. The original data is qualitative, thus to determine an appropriate number of replicates to initially perform, sample sizes based on a range of potential variance was determined. 
- See Power calculations for details.

- Each experiment consists of six cohorts:

- Cohort 1: control silenced D04 cells

- Cohort 2: control silenced D04 cells treated with SB590885

- Cohort 3: NRAS silenced D04 cells

- Cohort 4: NRAS silenced D04 cells treated with SB590885

- Cohort 5: CRAF silenced D04 cells

- Cohort 6: CRAF silenced D04 cells treated with SB590885

- Each cohort will be probed for NRAS, CRAF, PpMEK, $\alpha$ ppERK, and tubulin by Western blot

\section{Materials and reagents}

\begin{tabular}{|c|c|c|c|c|}
\hline Reagent & Type & Manufacturer & Cat. No. & Comments \\
\hline D04 cells & Cells & \multicolumn{3}{|c|}{$\begin{array}{l}\text { Provided by Chris Schmidt, Queensland Institute of } \\
\text { Medical Research (QIMR) Berghofer, Australia }\end{array}$} \\
\hline RPMI & Cell culture media & Life Technologies & \multicolumn{2}{|l|}{$21875-034$} \\
\hline FBS & Reagent & Life Technologies & \multicolumn{2}{|l|}{10270106} \\
\hline SB590885 & Drug & Selleckchem & $\mathrm{S} 2220$ & *Replaces Plexxion 885-A \\
\hline DMSO & Reagent & Fisher Scientific & D128-500 & Original not specified \\
\hline $35 \mathrm{~mm}$ tissue culture dishes & Materials & Corning & CLS430165 & Original not specified \\
\hline INTERFERin & Reagent & Polyplus Transfection & $409-01$ & \\
\hline CRAF siRNA & siRNA & \multicolumn{2}{|c|}{$\begin{array}{l}\text { Synthesis left to the discretion of the } \\
\text { replicating lab and will be recorded later }\end{array}$} & 5'-AAGCACGCTTAGATTG GAATA-3' \\
\hline NRAS siRNA & siRNA & \multicolumn{2}{|c|}{$\begin{array}{l}\text { Synthesis left to the discretion of the } \\
\text { replicating lab and will be recorded later }\end{array}$} & 5'-CATGGCACTGTACTCT TCTCG-3' \\
\hline Scrambled siRNA & siRNA & \multicolumn{2}{|c|}{$\begin{array}{l}\text { Synthesis left to the discretion of the } \\
\text { replicating lab and will be recorded later }\end{array}$} & 5'-AAACCGTC GATTTCACCCGGG-3' \\
\hline PBS & Reagent & Gibco & 10010-023 & Original not specified \\
\hline Tris- $\mathrm{HCl}$ & Chemical & \multirow{6}{*}{\multicolumn{3}{|c|}{$\begin{array}{l}\text { Specific brand information will be left up to the discretion } \\
\text { of the replicating lab and recorded later }\end{array}$}} \\
\hline $\mathrm{NaCl}$ & Chemical & & & \\
\hline lgepal & Chemical & & & \\
\hline $\mathrm{Na}_{3} \mathrm{VO}_{4}$ & Chemical & & & \\
\hline $\mathrm{NaF}$ & Chemical & & & \\
\hline Leupeptin & Chemical & & & \\
\hline Bradford Assay & Detection Assay & Bio-Rad Laboratories & 5000001 & Original not specified \\
\hline NuPAGE Sample buffer & Buffer & Invitrogen & NP0007 & Original not specified \\
\hline SDS-Page gel (4-12\%) & Western blot reagent & Invitrogen & NP0322BOX & Original not specified \\
\hline Nitrocellulose membrane (iBlot) & Western blot reagent & Invitrogen & IB301002 & Original not specified \\
\hline Ponceau stain & Western blot reagent & Sigma-Aldrich & P7170-1L & Original not specified \\
\hline Tris & Chemical & Sigma-Aldrich & T6066 & Original not specified \\
\hline Tween-20 & Chemical & Sigma-Aldrich & P1379 & Original not specified \\
\hline Mouse $\alpha$ NRAS (C-20) & Antibody & Santa Cruz Biotechnology & sc-159 & \\
\hline Mouse $\alpha$ CRAF & Antibody & BD Transduction Laboratories & 610152 & \\
\hline Rabbit $\alpha$ ppMEK1/2 & Antibody & Cell Signaling Technology & 9121 & \\
\hline Mouse $\alpha$ ppERK1/2 & Antibody & Sigma & M8159 & \\
\hline Mouse $\alpha$ tubulin & Antibody & Sigma & T5168 & \\
\hline HPR-conjugated secondary antibody & Western blot reagent & Bio-Rad & $170-5047$ & Original not specified \\
\hline ECL Detection Kit & Western blot reagent & Invitrogen & 32132 & Original not specified \\
\hline
\end{tabular}




\section{Procedure}

\section{Notes}

- All cells will be sent for mycoplasma testing and STR profiling.

- D04 cells are maintained in RPMI supplemented with $10 \%$ FBS.

- All cell lines are maintained at $37^{\circ} \mathrm{C}$ with $10 \% \mathrm{CO}_{2}$.

- SB590885 is dissolved in DMSO.

1. Seed $3 \times 10^{5}$ D04 cells per $35-\mathrm{mm}$ plate in $2 \mathrm{ml}$ media.

1. Let incubate overnight.

2. The next morning, prepare siRNA transfection mixture with INTERFERin according to the manufacturer's protocol, summarized here:

1. Mix $0.6 \mu$ of $20 \mu \mathrm{M}$ siRNA with $6 \mu \mathrm{l}$ INTERERin and $200 \mu \mathrm{l}$ of serum-free media in RNAsefree tubes.

1. CRAF siRNA: 5'-AAGCACGCTTAGATTGGAATA-3'

2. NRAS siRNA: 5'-CATGGCACTGTACTCTTCTCG-3'

3. Scrambled siRNA control: 5'-AAACCGTC GATTTCACCCGGG-3'

2. Vortex mixture for $10 \mathrm{~s}$.

3. Incubate for 5 to $10 \mathrm{~min}$.

4. Add mixture dropwise to seeded cells in complete media.

5. Incubate overnight.

3. The next day after transfection, replace with serum free media.

4. $48 \mathrm{hr}$ after siRNA transfection, treat cells with $1 \mu \mathrm{M}$ SB590885 or equivalent volume vehicle (DMSO, <0.2\%) for $4 \mathrm{hr}$.

5. Lyse cells and harvest extracts as described in Protocol 1 Step 3.

6. Perform Western blots on cell extracts as described in Protocol 1 Step 4.

a. Blot membranes with the following antibodies:

1. Rabbit $\alpha$ ppMEK: 1:1000 dilution

2. Rabbit $\alpha$ ppERK: 1:1000 dilution

3. Mouse $\alpha$ tubulin: 1:5000 dilution Western blot antibody multiplexing

\begin{tabular}{lllll}
\hline \multicolumn{2}{l}{ POI } & Loading control & \\
\hline Combination & Description & Working conc. & Description & Working conc. \\
\hline 1 & Rabit anti-ppMEK $(45 \mathrm{kDa})$ & $1: 1000$ & Mouse anti-tubulin $(50 \mathrm{kDa})$ & $1: 5000$ \\
\hline 2 & Rabbit anti-ppERK $(42,44 \mathrm{kDa})$ & $1: 1000$ & Mouse anti-tubulin $(50 \mathrm{kDa})$ & $1: 5000$ \\
\hline
\end{tabular}

4. Strip gels with glycine buffer ( $\mathrm{pH} 3.0$ ) containing $1 \%$ SDS

5. Confirm complete stripping and image membranes, block with milk/TBST, and reprobe each gel with one of the following antibodies:

1. Mouse $\alpha$ NRAS: 1:250 dilution

2. Mouse $\alpha$ CRAF: 1:1000 dilution

b. Quantify band intensity.

c. Normalize NRAS, CRAF, ppMEK, and ppERK to tubulin for each condition.

7. Repeat independently three additional times.

\section{Deliverables}

- Data to be collected:

- Protein quantification results from Bradford assay.

- Images of Ponceau stained membranes.

- Images of whole gels with ladder (as reported in Figure 1B).

- Densitometric quantification of all bands.

\section{Confirmatory analysis plan}

- Statistical Analysis of the Replication Data: 
Note: At the time of analysis, we will calculate Pearson's $r$ to check for correlation between the dependent variables, a scatter plot to assess linearity, and a Box's M test to check for equality of covariance matrices. We will also perform the Shapiro-Wilk test and generate a quantile-quantile plot to assess the normality of the data. We will perform Levene's test to assess homoscedasticity. If the data appears skewed, we will perform a transformation in order to proceed with the proposed statistical analysis. If this is not possible, we will perform the equivalent non-parametric test.

- One-way MANOVA comparing the differences between SB590885 treatment and vehicle treatment of normalized band intensities for pMEK and pERK levels in D04 cells transfected with siRNA for NRAS, CRAF, or control with the following Bonferroni-corrected comparisons:

- Difference in normalized ppMEK levels between SB590885 and vehicle treatment:

- Control siRNA compared to NRAS siRNA.

- Control siRNA compared to CRAF siRNA.

- Difference in normalized ppERK levels between SB590885 and vehicle treatment:

- Control siRNA compared to NRAS siRNA.

- Control siRNA compared to CRAF siRNA

- Meta-analysis of original and replication attempt effect sizes:

- The replication data (mean and 95\% confidence interval) will be plotted with the original quantified data value displayed as a single point on the same plot for comparison.

Known differences from the original study

The replication will replace 885-A with its analogue SB590885. The original authors suggest they have found similar results with this analogue (personal communication with Dr. Dhomen). All known differences, if any, are listed in the 'Materials and reagents' section above with the originally used item listed in the comments section. The comments section also lists if the source of original item was not specified. All differences have the same capabilities as the original and are not expected to alter the experimental design.

\section{Provisions for quality control}

Cells will be sent for mycoplasma testing confirming lack of contamination and STR profiling confirming cell line authenticity. The transfer efficiency during the Western blot procedure will be monitored by Ponceau staining. The membrane will be imaged after stripping to confirm and measure background. All data obtained from the experiment - raw data, data analysis, control data, and quality control data - will be made publicly available, either in the published manuscript or as an open access dataset available on the Open Science Framework (https://osf.io/b1aw6/).

\section{Protocol 3: Immunoprecipitation of CRAF from SB590885 treated D04 cells expressing myc-tagged CRAF ${ }^{\mathrm{WT}}$ or CRAF ${ }^{\mathrm{R} 8 \mathrm{~L}}$}

This protocol describes how to immunoprecipitate myc-tagged CRAFWT or CRAF ${ }^{\mathrm{R} 89 \mathrm{~L}}$, a mutant form that cannot bind RAS, from D04 cells and probe the pulldown for BRAF, as reported in Figure 3A.

\section{Sampling}

- The experiment will be performed independently at least three times for a final power of at least $80 \%$. The original data is qualitative, thus to determine an appropriate number of replicates to initially perform, sample sizes based on a range of potential variance was determined.

- See Power calculations for details.

- Each experiment consists of six cohorts:

- Cohort 1: D04 cells transfected with myc-tagged CRAF ${ }^{\mathrm{WT}}$ treated with SB590885

- Cohort 2: D04 cells transfected with myc-tagged CRAFWT treated with DMSO

- Cohort 3: D04 cells transfected with myc-tagged CRAF ${ }^{\mathrm{R} 89 \mathrm{~L}}$ treated with SB590885

- Cohort 4: D04 cells transfected with myc-tagged CRAF ${ }^{R 9 L}$ treated with DMSO

- Cohort 5: D04 cells transfected with empty vector treated with SB590885

- Cohort 6: D04 cells transfected with empty vector treated with DMSO

- Each cohort will be immunoprecipitated for myc-tagged CRAF and immunoprecipitate and lysates probed for BRAF and myc. 
Materials and reagents

\begin{tabular}{|c|c|c|c|c|}
\hline Reagent & Type & Manufacturer & Catalog \# & Comments \\
\hline D04 cells & Cells & \multicolumn{3}{|c|}{$\begin{array}{l}\text { Provided by Chris Schmidt, Queensland Institute of } \\
\text { Medical Research (QIMR) Berghofer, Australia }\end{array}$} \\
\hline SB590885 & Drug & Selleckchem & S2220 & *Replaces Plexxion 885-A \\
\hline DMSO & Reagent & Fisher Scientific & D128-500 & Original not specified \\
\hline RPMI & Media & Life Technologies & $21875-034$ & \\
\hline FBS & Reagent & Life Technologies & 10270106 & \\
\hline Effectene Transfection Reagent & Reagent & Qiagen & 301425 & $\begin{array}{l}\text { Replaces Cell Line Nucleofector } \\
\text { Kit V (10 RCT) Lonza VACA1003 }\end{array}$ \\
\hline $35 \mathrm{~mm}$ culture dishes & Materials & Corning & CLS430165 & Original not specified \\
\hline Myc-CRAF ${ }^{\mathrm{WT}}$ vector & Plasmid & \multicolumn{3}{|l|}{ Shared by original authors } \\
\hline Myc-CRAF ${ }^{R 89 L}$ vector & Plasmid & \multicolumn{3}{|l|}{ Shared by original authors } \\
\hline Empty vector & Plasmid & \multicolumn{3}{|l|}{ Shared by original authors } \\
\hline PBS & Reagent & Gibco & $10010-023$ & Original not specified \\
\hline Tris- $\mathrm{HCl}$ & Chemical & \multirow{6}{*}{\multicolumn{3}{|c|}{$\begin{array}{l}\text { Specific brand information will be left up to the discretion } \\
\text { of the replicating lab and recorded later }\end{array}$}} \\
\hline $\mathrm{NaCl}$ & Chemical & & & \\
\hline lgepal & Chemical & & & \\
\hline $\mathrm{Na}_{3} \mathrm{VO}_{4}$ & Chemical & & & \\
\hline $\mathrm{NaF}$ & Chemical & & & \\
\hline Leupeptin & Chemical & & & \\
\hline Rabbit $\alpha$ myc & Antibody & Abcam & ab9106 & \\
\hline Mouse $\alpha$ BRAF (F-7) & Antibody & Santa Cruz Biotechnology & sc-5284 & \\
\hline Mouse $\alpha$ myc (9B11) (HRP conjugate) & Antibody & Cell Signaling Technology & 2040 & \\
\hline Protein G sepharose beads & Materials & Sigma & P3296 & \\
\hline NuPAGE Sample buffer & Buffer & Invitrogen & NP0007 & Original not specified \\
\hline SDS-Page gel (4-12\%) & Western blot reagent & Invitrogen & NP0322BOX & Original not specified \\
\hline Nitrocellulose membrane (iBlot) & Western blot reagent & Invitrogen & IB301002 & Original not specified \\
\hline Ponceau stain & Western blot reagent & Sigma-Aldrich & P7170-1L & Original not specified \\
\hline Tris & Chemical & Sigma-Aldrich & T6066 & Original not specified \\
\hline Tween-20 & Chemical & Sigma-Aldrich & P1379 & Original not specified \\
\hline HPR-conjugated secondary antibody & Western blot reagent & Bio-Rad & $170-5047$ & Original not specified \\
\hline ECL Detection Kit & Western blot reagent & Invitrogen & 32132 & Original not specified \\
\hline
\end{tabular}

\section{Procedure}

Notes

- All cells will be sent for mycoplasma testing and STR profiling.

- D04 cells are maintained in RPMI supplemented with 10\% FBS.

- All cell lines are maintained at $37^{\circ} \mathrm{C}$ with $10 \% \mathrm{CO}_{2}$.

- SB590885 is dissolved in DMSO.

1. Transfect $\mathrm{D} 04$ cells with vectors containing myc-tagged $C R A F^{\mathrm{wt}}$ or $\mathrm{CRAF}^{\mathrm{R} 89 \mathrm{~L}}$.

1. "Plate $1 \times 10^{6}$ cells per well of a six-well plate with $1.6 \mathrm{ml}$ media 1 day before transfection. The cells should be $40-80 \%$ confluent on the day of transfection.

2. "On the day of transfection, dilute $0.4 \mu \mathrm{g}$ of DNA for each vector in TE buffer, $\mathrm{pH} 7$ with the DNA-condensation buffer, Buffer EC, to a total volume of $100 \mu \mathrm{l}$. Add $3.2 \mu \mathrm{l}$ Enhancer and mix by vortexing. 
1. Empty vector

2. Myc-CRAF ${ }^{\mathrm{WT}}$ vector

3. Myc-CRAF $^{\text {R89L }}$ vector

3. "Incubate at room temperature for $5 \mathrm{~min}$, centrifuge quickly.

4. " Add $10 \mu$ l Effectene Transfection Reagent to the DNA-Enhancer mixture and mix by pipetting.

5. "Incubate at room temperature for $10 \mathrm{~min}$.

6. "Gently aspirate the medium from the plated cells and wash once with $2 \mathrm{ml}$ PBS. Add 1.6 $\mathrm{ml}$ fresh medium to the cells.

7. " Add $600 \mu \mathrm{l}$ medium to the tube containing transfection complexes and mix by pipetting. Immediately add transfection complexes drop-wise onto plated cells. Gently swirl to mix.

8. "Incubate for $18 \mathrm{hr}$ after transfection. Replace with fresh medium.

2. $48 \mathrm{hr}$ after transfection, treat cells with $1 \mu \mathrm{M}$ SB590885 or equivalent volume vehicle (DMSO, $<0.2 \%)$ for $4 \mathrm{hr}$.

3. Lyse cells and prepare cell lysate as described in Protocol 1 Step 3.

1. Save 5-15 $\mu \mathrm{g}$ protein from each lysate to confirm transfection by Western blot below.

4. Immunoprecipitate myc-tagged CRAF proteins

Note: 2-3 $35 \mathrm{~mm}$ wells of protein lysed in $300 \mu \mathrm{l}$ NP40 buffer are needed for IP reaction.

1. Immunoprecipitate the Myc-tagged proteins by adding $2 \mu \mathrm{g}$ rabbit anti-myc antibody and incubate overnight at $4^{\circ} \mathrm{C}$.

2. Capture the antibody-protein complex by adding $20 \mu \mathrm{l}$ of a 1:1 Protein $\mathrm{G}$ sepharose $4 \mathrm{~B}$ beads mixture in NP40 extraction buffer.

1. NP40 extraction buffer: $50 \mathrm{mM}$ Tris- $\mathrm{HCl}, \mathrm{pH} 7.5,150 \mathrm{mM} \mathrm{NaCl}, 0.55$ (v/v) lgepal, 5 $\mathrm{mM} \mathrm{NaF}, 0.2 \mathrm{mM} \mathrm{Na}_{3} \mathrm{VO}_{4}, 5 \mu \mathrm{g} / \mathrm{ml}$ leupeptin.

2. Incubate on ice for $5 \mathrm{~min}$.

3. Mix on a rotating wheel for $2 \mathrm{hr}$ at $4^{\circ} \mathrm{C}$.

3. Wash IPs three times with $300 \mu$ I NP40 extraction buffer.

4. Elute protein complex from beads with NuPage sample buffer

5. Run IPs and lysate on an SDS-PAGE gel as described in Protocol 1 Step 4.

1. Probe with the following antibodies:

1. Mouse $\alpha$ BRAF: 1:2000 dilution

2. Mouse $\alpha$ myc: 1:1000 dilution

2. Quantify band intensity.

3. Normalize IP $\alpha$ BRAF to IP $\alpha$ myc-CRAF for each condition from IP band intensities.

6. Repeat independently two additional times.

\section{Deliverables}

- Data to be collected:

- Protein quantification results from Bradford assay.

- Images of Ponceau stained membranes.

- Transfection QC images of whole gels with ladder.

- Images of whole gels with ladder (as reported in Figure 3A).

- Densitometric quantification of all bands.

\section{Confirmatory analysis plan}

- Statistical Analysis of the Replication Data:

Note: At the time of analysis, we will perform the Shapiro-Wilk test and generate a quantile-quantile plot to assess the normality of the data. We will also perform Levene's test to assess homoscedasticity. If the data appears skewed, we will perform a transformation in order to proceed with the proposed statistical analysis. If this is not possible, we will perform the equivalent non-parametric test listed.

- Two-way ANOVA comparing normalized IP BRAF (to IP $\alpha$ myc) band intensity in D04 cells transfected with Myc-CRAFWT vector or Myc-CRAF ${ }^{R 89 L}$ vector with or without SB590885 drug treatment, and the following Bonferroni-corrected comparisons:

- Normalized IP BRAF band intensity in cells with Myc-CRAFWT vector with SB590885 treatment vs. vehicle treatment. 
- Normalized IP BRAF band intensity in cells with Myc- CRAF ${ }^{\text {R89 }}$ vector with SB590885 treatment vs. vehicle treatment.

- Meta-analysis of original and replication attempt effect sizes:

- The replication data (mean and 95\% confidence interval) will be plotted with the original quantified data value displayed as a single point on the same plot for comparison.

Known differences from the original study

The transfection method using Nucleofectin Solution $V$ and electroporation will be replaced with a lipid-based method using Effectene Transfection Reagent, and protocol will be changed according to Manufacturer's instructions. This difference in transfection protocol might lead to differences in expression that could lead to differences in results. The replication will replace $885-\mathrm{A}$ with its analogue SB590885. The original authors suggest they have found similar results with this analogue (personal communication with Dr. Dhomen). All known differences, if any, are listed in the 'Materials and reagents' section above with the originally used item listed in the comments section. The comments section also lists if the source of original item was not specified. All differences have the same capabilities as the original and are not expected to alter the experimental design.

Provisions for quality control

Cells will be sent for mycoplasma testing confirming lack of contamination and STR profiling confirming cell line authenticity. Transfection will be confirmed with Western blot. The transfer efficiency during the Western blot procedure will be monitored by Ponceau staining. All data obtained from the experiment - raw data, data analysis, control data, and quality control data - will be made publicly available, either as a published manuscript or as an open access dataset available on the Open Science Framework (https://osf.io/b1aw6/).

\section{Protocol 4: Immunoprecipitation of BRAF from SB590885 treated D04 cells expressing myc-tagged BRAF ${ }^{W T}$ or $B R A F^{R 188 L}$}

This protocol describes how to immunoprecipitate myc-tagged BRAF ${ }^{\mathrm{WT}}$ or BRAF ${ }^{\mathrm{R} 188 \mathrm{~L}}$, a mutant form that cannot bind RAS, from D04 cells and probe the pulldown for CRAF, as reported in Figure 3B.

\section{Sampling}

- The experiment will be performed independently at least three times for a final power of at least $80 \%$. The original data is qualitative, thus to determine an appropriate number of replicates to initially perform, sample sizes based on a range of potential variance was determined.

- See Power calculations for details.

- Each experiment consists of six cohorts:

- Cohort 1: D04 cells transfected with myc-tagged BRAFWT treated with SB590885

- Cohort 2: D04 cells transfected with myc-tagged BRAFWT treated with DMSO

- Cohort 3: D04 cells transfected with myc-tagged BRAF ${ }^{\mathrm{R} 188 \mathrm{~L}}$ treated with SB590885

- Cohort 4: D04 cells transfected with myc-tagged BRAF ${ }^{\mathrm{R} 188 \mathrm{~L}}$ treated with DMSO

- Cohort 5: D04 cells transfected with empty vector treated with SB590885

- Cohort 6: D04 cells transfected with empty vector treated with DMSO

- Each cohort will be immunoprecipitated for myc-tagged BRAF and immunoprecipitate and lysates probed for CRAF and myc.

Materials and reagents

\begin{tabular}{lllc} 
Reagent & Type & Manufacturer & Catalog \# Comments \\
\hline D04 cells & Cells & Provided by Chris Schmidt, Queensland Institute of \\
& & Medical Research (QIMR) Berghofer, Australia
\end{tabular}


Continued

\begin{tabular}{|c|c|c|c|c|}
\hline Reagent & Type & Manufacturer & Catalog \# & Comments \\
\hline DMSO & Reagent & Fisher Scientific & D128-500 & Original not specified \\
\hline RPMI & Media & Life Technologies & $21875-034$ & \\
\hline FBS & Reagent & Life Technologies & 10270106 & \\
\hline Effectene Transfection Reagent & Reagent & Qiagen & 301425 & $\begin{array}{l}\text { Replaces Cell Line } \\
\text { Nucleofector Kit V (10 RCT) } \\
\text { Lonza VACA1003 }\end{array}$ \\
\hline 35-mm culture dishes & Materials & Corning & CLS430165 & Original not specified \\
\hline Myc-BRAF ${ }^{W T}$ vector & Plasmid & Shared by original authors & & \\
\hline Myc-BRAF ${ }^{R 188 L}$ vector & Plasmid & Shared by original authors & & \\
\hline Empty vector & Plasmid & Shared by original authors & & \\
\hline PBS & Reagent & Gibco & $10010-023$ & Original not specified \\
\hline Tris- $\mathrm{HCl}$ & Chemical & \multirow{6}{*}{\multicolumn{2}{|c|}{$\begin{array}{l}\text { Specific brand information will be left up to the } \\
\text { of the replicating lab and recorded later }\end{array}$}} & retion \\
\hline $\mathrm{NaCl}$ & Chemical & & & \\
\hline lgepal & Chemical & & & \\
\hline $\mathrm{Na}_{3} \mathrm{VO}_{4}$ & Chemical & & & \\
\hline $\mathrm{NaF}$ & Chemical & & & \\
\hline Leupeptin & Chemical & & & \\
\hline Rabbit anti-myc & Antibody & Abcam & ab9106 & \\
\hline mouse anti-CRAF & Antibody & BD Transduction Laboratories & 610152 & \\
\hline Mouse $\alpha$ myc (9B11) (HRP conjugate) & Antibody & Cell Signaling Technology & 2040 & \\
\hline Protein G sepharose beads & Materials & Sigma & P3296 & \\
\hline NuPAGE Sample buffer & Buffer & Invitrogen & NP0007 & Original not specified \\
\hline SDS-Page gel (4-12\%) & Western blot reagent & Invitrogen & NP0322BOX & Original not specified \\
\hline Nitrocellulose membrane (iBlot) & Western blot reagent & Invitrogen & IB301002 & Original not specified \\
\hline Ponceau stain & Western blot reagent & Sigma-Aldrich & P7170-1L & Original not specified \\
\hline Tris & Chemical & Sigma-Aldrich & T6066 & Original not specified \\
\hline Tween-20 & Chemical & Sigma-Aldrich & P1379 & Original not specified \\
\hline HPR-conjugated secondary antibody & Western blot reagent & Bio-Rad & $170-5047$ & Original not specified \\
\hline ECL Detection Kit & Western blot reagent & Invitrogen & 32132 & Original not specified \\
\hline
\end{tabular}

Procedure

Notes:

- All cells will be sent for mycoplasma testing and STR profiling.

- D04 cells are maintained in RPMI supplemented with 10\% FBS.

- All cell lines are maintained at $37^{\circ} \mathrm{C}$ with $10 \% \mathrm{CO}_{2}$.

- SB590885 is dissolved in DMSO.

1. Transfect $D 04$ cells with vectors containing myc-tagged $B R A F^{w t}$ or $B R A F^{R} 188 L$ as described in Protocol 3 Step 1.

2. $48 \mathrm{hr}$ after transfection, treat cells with $1 \mu \mathrm{M}$ SB590885 or equivalent volume vehicle (DMSO, $<0.2 \%$ ) for $4 \mathrm{hr}$

3. Lyse cells and prepare cell lysate as described in Protocol 1 Step 3.

1. Save 5-15 $\mu \mathrm{g}$ protein from each lysate to confirm transfection by Western blot below.

4. Immunoprecipitate myc-tagged CRAF proteins

Note: 2-3 $35 \mathrm{~mm}$ wells of protein lysed in $300 \mu$ I NP40 buffer are needed for IP reaction.

1. Immunoprecipitate the Myc-tagged proteins by adding $2 \mu \mathrm{g}$ rabbit anti-myc antibody and incubate overnight at $4^{\circ} \mathrm{C}$. 
2. Capture the antibody-protein complex by adding $20 \mu \mathrm{l}$ of a 1:1 Protein $\mathrm{G}$ sepharose $4 \mathrm{~B}$ beads mixture in NP40 extraction buffer.

1. NP40 extraction buffer: $50 \mathrm{mM}$ Tris- $\mathrm{HCl}, \mathrm{pH} 7.5,150 \mathrm{mM} \mathrm{NaCl}, 0.55$ (v/v) lgepal, 5 $\mathrm{mM} \mathrm{NaF}, 0.2 \mathrm{mM} \mathrm{Na}_{3} \mathrm{VO}_{4}, 5 \mu \mathrm{g} / \mathrm{ml}$ leupeptin.

2. Incubate on ice for $5 \mathrm{~min}$.

3. Mix on a rotating wheel for $2 \mathrm{hr}$ at $4^{\circ} \mathrm{C}$.

3. Wash IPs three times with $300 \mu$ I NP40 extraction buffer.

4. Elute protein complex from beads with NuPage sample buffer

5. Run IPs and lysate on an SDS-PAGE gel as described in Protocol 1 Step 4.

1. Probe with the following antibodies:

1. Mouse $\alpha$ CRAF: 1:1000 dilution

2. Mouse $\alpha$ myc: 1:1000 dilution

2. Quantify band intensity.

3. Normalize IP $\alpha$ CRAF to IP $\alpha$ myc-BRAF for each condition from IP band intensities.

6. Repeat independently two additional times.

\section{Deliverables}

- Data to be collected:

- Protein quantification results from Bradford assay.

- Images of Ponceau stained membranes.

- Transfection QC images of whole gels with ladder.

- Images of whole gels with ladder (as reported in Figure 3A).

- Densitometric quantification of all bands.

\section{Confirmatory analysis plan}

- Statistical Analysis of the Replication Data:

Note: At the time of analysis, we will perform the Shapiro-Wilk test and generate a quantile-quantile plot to assess the normality of the data. We will also perform Levene's test to assess homoscedasticity. If the data appears skewed, we will perform a transformation in order to proceed with the proposed statistical analysis. If this is not possible, we will perform the equivalent non-parametric test listed.

- Two-way ANOVA comparing normalized IP CRAF (to IP $\alpha$ myc) band intensity in D04 cells transfected with Myc-BRAF ${ }^{\mathrm{WT}}$ vector or Myc-BRAF ${ }^{\mathrm{R} 188 \mathrm{~L}}$ vector with or without SB590885 drug treatment, and the following Bonferroni-corrected comparisons:

- Normalized IP CRAF band intensity in cells with Myc-BRAFWT vector with SB590885 treatment vs. vehicle treatment.

- Normalized IP CRAF band intensity in cells with Myc- BRAF ${ }^{\mathrm{R} 188 \mathrm{~L}}$ vector with SB590885 treatment vs. vehicle treatment.

- Meta-analysis of original and replication attempt effect sizes:

- The replication data (mean and 95\% confidence interval) will be plotted with the original quantified data value displayed as a single point on the same plot for comparison.

\section{Known differences from the original study}

The transfection method using Nucleofectin Solution $V$ and electroporation will be replaced with a lipid-based method using Effectene Transfection Reagent, and protocol will be changed according to Manufacturer's instructions. The replication will replace 885-A with its analogue SB590885. The original authors suggest they have found similar results with this analogue (personal communication with Dr. Dhomen). All known differences, if any, are listed in the 'Materials and reagents' section above with the originally used item listed in the comments section. The comments section also lists if the source of original item was not specified. All differences have the same capabilities as the original and are not expected to alter the experimental design. 
Provisions for quality control

Cells will be sent for mycoplasma testing confirming lack of contamination and STR profiling confirming cell line authenticity. Transfection will be confirmed with Western blot. The transfer efficiency during the Western blot procedure will be monitored by Ponceau staining. All data obtained from the experiment - raw data, data analysis, control data, and quality control data - will be made publicly available, either as a published manuscript or as an open access dataset available on the Open Science Framework (https://osf.io/b1aw6/).

\section{Protocol 5: Expression of BRAF kinase dead mutant in D04 cells and its effect on CRAF binding}

This protocol describes how to transiently express myc-tagged BRAFWT or BRAF ${ }^{\mathrm{D} 59 \mathrm{~A}}$ in D04 cells and assess CRAF binding by immunoprecipitation and blotting, as reported in Figure 4D.

\section{Sampling}

- The experiment will be performed independently at least three times for a minimum power of $80 \%$. The original data is qualitative, thus to determine an appropriate number of replicates to initially perform, sample sizes based on a range of potential variance was determined.

- See Power Calculations for details.

- Each experiment consists of three cohorts:

- Cohort 1: D04 cells transfected with myc-tagged BRAFWT

- Cohort 2: D04 cells transfected with myc-tagged BRAF ${ }^{\mathrm{D} 544 \mathrm{~A}}$

- Cohort 3: D04 cells transfected with empty vector

- Untreated cells are immunoprecipitated with $\alpha$ myc and levels of myc-BRAF and CRAF are assessed by immunoblotting.

\section{Materials and reagents}

\begin{tabular}{|c|c|c|c|c|}
\hline Reagent & Type & Manufacturer & Catalog \# & Comments \\
\hline D04 cells & Cells & \multicolumn{3}{|c|}{$\begin{array}{l}\text { Provided by Chris Schmidt, Queensland Institute of } \\
\text { Medical Research (QIMR) Berghofer, Australia }\end{array}$} \\
\hline RPMI & Media & Life Technologies & $21875-034$ & \\
\hline FBS & Reagent & Life Technologies & 10270106 & \\
\hline Effectene Transfection Reagent & Reagent & Qiagen & 301425 & $\begin{array}{l}\text { Replaces Cell Line Nucleofector } \\
\text { Kit V (10 RCT) Lonza VACA1003 }\end{array}$ \\
\hline Myc-BRAF ${ }^{W T}$ vector & Plasmid & \multicolumn{3}{|l|}{ Shared by original author } \\
\hline Myc-BRAF ${ }^{\mathrm{D} 594 \mathrm{~A}}$ vector & Plasmid & \multicolumn{3}{|l|}{ Shared by original author } \\
\hline Empty vector & Plasmid & \multicolumn{3}{|l|}{ Shared by original author } \\
\hline $35 \mathrm{~mm}$ culture dishes & Materials & & & \\
\hline PBS & Reagent & Gibco & $10010-023$ & Original not specified \\
\hline Tris- $\mathrm{HCl}$ & Chemical & \multirow{6}{*}{\multicolumn{3}{|c|}{$\begin{array}{l}\text { Specific brand information will be left up to the discretion } \\
\text { of the replicating lab and recorded later }\end{array}$}} \\
\hline $\mathrm{NaCl}$ & Chemical & & & \\
\hline Igepal & Chemical & & & \\
\hline $\mathrm{Na}_{3} \mathrm{VO}_{4}$ & Chemical & & & \\
\hline $\mathrm{NaF}$ & Chemical & & & \\
\hline Leupeptin & Chemical & & & \\
\hline Rabbit $\alpha$ myc & Antibody & Abcam & \multicolumn{2}{|l|}{ ab9106 } \\
\hline Mouse $\alpha$ CRAF (for Western blotting) & Antibody & BD Transduction Laboratories & \multicolumn{2}{|l|}{610152} \\
\hline Mouse $\alpha$ myc (9B11) (HRP conjugate) & Antibody & Cell Signaling Technology & \multicolumn{2}{|l|}{2040} \\
\hline Protein $G$ sepharose beads & Materials & Sigma & \multicolumn{2}{|l|}{ P3296 } \\
\hline
\end{tabular}

Continued on next page 
Continued

\begin{tabular}{lllll} 
Reagent & Type & Manufacturer & Catalog \# & Comments \\
\hline NuPAGE Sample buffer & Buffer & Invitrogen & NP0007 & Original not specified \\
\hline SDS-Page gel (4-12\%) & Western blot reagent & Invitrogen & NP0322BOX & Original not specified \\
\hline Nitrocellulose membrane (iBlot) & Western blot reagent & Invitrogen & IB301002 & Original not specified \\
\hline Ponceau stain & Western blot reagent & Sigma-Aldrich & P7170-1L & Original not specified \\
\hline Tris & Chemical & Sigma-Aldrich & T6066 & Original not specified \\
\hline Tween-20 & Chemical & Sigma-Aldrich & P1379 & Original not specified \\
\hline HPR-conjugated secondary antibody & Western blot reagent & Bio-Rad & 170-5047 & Original not specified \\
\hline ECL Detection Kit & Western blot reagent & Invitrogen & 32132 & Original not specified
\end{tabular}

Procedure

Notes:

- All cells will be sent for mycoplasma testing and STR profiling.

- D04 cells are maintained in RPMI supplemented with $10 \%$ FBS.

- All cell lines are maintained at $37^{\circ} \mathrm{C}$ with $10 \% \mathrm{CO}_{2}$.

1. Transiently transfect D04 cells with the following vectors as described in Protocol 3 step 1.

1. Myc-BRAF ${ }^{\mathrm{WT}}$ vector

2. Myc-BRAF ${ }^{\mathrm{D} 594 \mathrm{~A}}$ vector

3. Empty vector

2. Lyse cells and prepare cell lysates as described in Protocol 1 Step 3.

1. Save 5-15 $\mu \mathrm{g}$ protein from each lysate to confirm transfection by Western blot below.

3. Immunoprecipitate myc-tagged BRAF proteins as described in Protocol 3 Step 4.

4. Run IPs and lysate on SDS-PAGE gel as described in Protocol 1 Step 4.

1. Probe with the following antibodies:

1. Mouse $\alpha$ CRAF: 1:1000 dilution

2. Mouse $\alpha$ myc: 1:1000 dilution

2. Quantify band intensity.

3. Normalize IP $\alpha$ CRAF to IP $\alpha$ myc-BRAF for each condition from IP band intensities.

5. Repeat independently two additional times.

\section{Deliverables}

- Data to be collected:

- Protein quantification results from Bradford assay.

- Images of Ponceau stained membranes.

- Images of whole gels (as reported in Figure 4D).

- Densitometric quantification of all bands.

- Any data pertaining to cell growth conditions optimization, if performed.

\section{Confirmatory analysis plan}

- Statistical Analysis of the Replication Data:

- A two sample Welch's t-test comparing normalized IP CRAF (using IP myc-BRAF band intensity) in D04 cells transfected with Myc-BRAF ${ }^{\mathrm{WT}}$ vector vs. Myc-BRAF ${ }^{\mathrm{D} 594 \mathrm{~A}}$ vector

- Meta-analysis of original and replication attempt effect sizes:

- The replication data (mean and 95\% confidence interval) will be plotted with the original quantified data value displayed as a single point on the same plot for comparison. 
Known differences from the original study

All known differences, if any, are listed in the 'Materials and reagents' section above with the originally used item listed in the comments section. The comments section also lists if the source of original item was not specified. All differences have the same capabilities as the original and are not expected to alter the experimental design.

Provisions for quality control

Cells will be sent for mycoplasma testing confirming lack of contamination and STR profiling confirming cell line authenticity. Transfection will be confirmed with Western blot. The transfer efficiency during the Western blot procedure will be monitored by Ponceau staining. All data obtained from the experiment - raw data, data analysis, control data, and quality control data - will be made publicly available, either as a published manuscript or as an open access dataset available on the Open Science Framework (https://osf.io/b1aw6/). Cells will be sent for mycoplasma testing confirming lack of contamination and STR profiling confirming cell line authenticity.

Power calculations

For additional details on power calculations, please see analysis scripts and associated files on the Open Science Framework:

https://osf.io/eaktg/

\section{Protocol 1}

\section{Summary of original data}

- The original data presented is qualitative (images of Western blots). We used Image Studio Lite (LICOR) to perform densitometric analysis of the presented bands. We then performed a priori power calculations with a range of assumed standard deviations to determine the number of replicates to perform.

- Note: band intensity quantified from the image reported in Figure 1A:

\begin{tabular}{llll} 
Cell type & Drug & $\begin{array}{l}\text { Band intensity normalized } \\
\text { total ERK }\end{array}$ & Assumed $\mathbf{N}$ \\
\hline A375 & 1.3864 & 3 \\
\cline { 2 - 4 } & Control & 0.0127 & 3 \\
\hline PD & 0.0257 & 3 \\
\hline SF & 0.0510 & 3 \\
\hline D04 & 0.1315 & 3 \\
\hline Control & 0.0198 & 3 \\
\hline PD & 0.0123 & 3 \\
\hline SF & 0.6650 & 3 \\
\hline
\end{tabular}

- The original data does not indicate the error associated with multiple biological replicates. To identify a suitable sample size, power calculations were performed using different levels of relative variance.

\section{Test family}

- Two-way ANOVA (2 x 4) fixed effects, special, main effects and interactions; alpha error $=0.05$ followed by Bonferroni corrected comparisons 


\section{Power calculations}

- Power calculations were performed using R software version 3.2.1 ( $R$ Core Team, 2014) and G*Power (version 3.1.7) (Faul et al., 2007)

\begin{tabular}{lllllll} 
Groups & Estimated variance & $\begin{array}{l}\mathbf{F} \text { test statistic } \\
\mathbf{F}_{(3,16) \text { interaction }}\end{array}$ & Partial $\eta^{2}$ & Effect size $\boldsymbol{f}$ & A priori power & $\begin{array}{l}\text { Total sample size } \\
(\mathbf{8} \text { groups) }\end{array}$ \\
\hline $\begin{array}{l}\text { A375 or D04 cells treated } \\
\text { with drugs or control }\end{array}$ & $2 \%$ & 7743.50 & 0.9993 & 38.112 & $99.9 \%$ & 9 \\
\cline { 2 - 7 } & $15 \%$ & 137.662 & 0.9627 & 5.080 & $98.8 \%$ & 10 \\
\cline { 2 - 7 } & $28 \%$ & 39.507 & 0.8811 & 2.722 & $96.0 \%$ & 11 \\
& $40 \%$ & 19.359 & 0.7840 & 1.905 & $91.6 \%$ & 12 \\
\hline
\end{tabular}

Test family

- F test, ANOVA: Fixed effects, special, main effects and interactions, Bonferroni's correction: alpha error $=0.01667$

Power Calculations performed with G*Power software, version 3.1.7 (Faul et al., 2007).

ANOVA $F$ test statistic and partial $\eta^{2}$ performed with $R$ software, version 3.2.1 (Team, 2015). Partial $\eta^{2}$ calculated from (Lakens, 2013).

For A375 cells, comparisons are between DMSO and all Drug Treatments (PD184352, sorafenib, and 885-A)

\begin{tabular}{|c|c|c|c|c|c|c|c|}
\hline Groups & Cell line & Variance estimate & $\begin{array}{l}\text { F test statistic } \\
\mathrm{Fc}_{(1,16)}\end{array}$ & Partial $\eta^{2}$ & Effect size $f$ & A priori power & $\begin{array}{l}\text { Total sample size } \\
\text { (8 groups) }\end{array}$ \\
\hline \multirow{4}{*}{$\begin{array}{l}\text { DMSO vs all Drug } \\
\text { Treatments }\end{array}$} & A375 & $2 \%$ & 34711.2 & 0.9995 & 46.58 & $99.9 \%$ & 9 \\
\hline & A375 & $15 \%$ & 617.09 & 0.9747 & 6.210 & $99.8 \%$ & 10 \\
\hline & A375 & $28 \%$ & 177.10 & 0.9171 & 3.327 & $84.2 \%$ & 10 \\
\hline & A375 & $40 \%$ & 86.78 & 0.8443 & 2.329 & $92.7 \%$ & 11 \\
\hline
\end{tabular}

For D04 cells, comparisons are between DMSO and PD184352 and sorafenib, and between DMSO and 885-A

\begin{tabular}{|c|c|c|c|c|c|c|c|}
\hline Groups & Cell line & Variance estimate & $\begin{array}{l}\mathrm{F} \text { test statistic } \\
\mathrm{Fc}_{(1,16)}\end{array}$ & Partial $\eta^{2}$ & Effect size $f$ & A priori power & $\begin{array}{l}\text { Total sample size } \\
\text { (8 groups) }\end{array}$ \\
\hline \multirow{4}{*}{$\begin{array}{l}\text { DMSO vs. PD184352 } \\
\text { and sorafenib }\end{array}$} & D04 & $2 \%$ & 223.55 & 0.9332 & 3.7379 & $90.2 \%$ & 10 \\
\hline & D04 & $15 \%$ & 3.9741 & 0.1990 & 0.4984 & $80.4 \%$ & 46 \\
\hline & D04 & $28 \%$ & 1.1405 & 0.0665 & 0.2670 & $80.0 \%$ & 150 \\
\hline & D04 & $40 \%$ & 0.5589 & 0.0337 & 0.1869 & $80.0 \%$ & 303 \\
\hline \multirow[t]{4}{*}{ DMSO vs. 885A } & D04 & $2 \%$ & 3580.31 & 0.9955 & 14.959 & $99.9 \%$ & 10 \\
\hline & D04 & $15 \%$ & 63.6498 & 0.7991 & 1.9945 & $84.0 \%$ & 11 \\
\hline & D04 & $28 \%$ & 18.2668 & 0.5331 & 1.0685 & $80.8 \%$ & 15 \\
\hline & D04 & $40 \%$ & 8.9507 & 0.3587 & 0.7479 & $80.1 \%$ & 23 \\
\hline
\end{tabular}

- Based on these power calculations, we will run the experiment three times. Each time, we will quantify band intensity. We will determine the standard deviation of band intensity across the biological replicates and combine this with the effect size from the original study to calculate the number of replicates necessary to reach a power of at least $80 \%$. We will then perform additional replicates, if required, to ensure the experiment has more than $80 \%$ power to detect the original effect. 


\section{Protocol 2}

\section{Summary of original data}

- The original data presented is qualitative (images of Western blots). We used Image Studio Lite (LICOR) to perform densitometric analysis of the presented bands. We then performed a priori power calculations with a range of assumed standard deviations to determine the number of replicates to perform.

- Note: band intensity quantified from the image reported in Figure 1B:

\begin{tabular}{|c|c|c|c|}
\hline Target & SiRNA & $\begin{array}{l}\text { Band intensity normalized } \\
\text { to tubulin for } \\
\text { transfected cells } \\
\text { treated with } 885-A \text { minus DMSO }\end{array}$ & Assumed $\mathbf{N}$ \\
\hline \multirow[t]{3}{*}{ pMEK } & Control & 0.836493931 & 3 \\
\hline & NRAS & 0.0695447 & 3 \\
\hline & CRAF & 0.3538748 & 3 \\
\hline \multirow[t]{3}{*}{ pERK } & Control & 0.8769868 & 3 \\
\hline & NRAS & 0.498252598 & 3 \\
\hline & CRAF & 0.653649416 & 3 \\
\hline
\end{tabular}

\section{Test family}

- Due to the lack of raw original data, we are unable to perform power calculations using a MANOVA. We are determining sample size using two one-way ANOVAs.

- Two, one-way ANOVAs (Bonferroni corrected) on the difference in the normalized band intensity for PMEK and pERK separately in transfected cells treated with 885-A minus DMSO followed by Bonferroni corrected comparisons for the following groups:

- $\mathrm{pMEK}$ and pERK each:

- Compare the difference in band intensity in cells transfected with control siRNA and treated with 885-A minus control siRNA with DMSO (Control siRNA Difference) vs. the difference in band intensity in cells transfected with NRAS siRNA and treated with 885-A minus NRAS siRNA with DMSO (NRAS siRNA Difference)

- Compare the difference in band intensity in cells transfected with control siRNA and treated with 885-A minus control siRNA with DMSO (Control siRNA Difference) vs. the difference in band intensity in cells transfected with CRAF siRNA and treated with 885-A minus CRAF siRNA with DMSO (CRAF siRNA Difference)

\section{Power calculations}

- Power calculations were performed using R software version 3.1.2 (R Core Team, 2014) and G*Power (version 3.1.7) (Faul et al., 2007)

PMEK

- $2 \%$ variance:

- ANOVA: Fixed effects, omnibus, one-way, Bonferroni corrected alpha error $=0.025$

\begin{tabular}{llllll} 
Groups & F test statistic & Partial $\eta^{2}$ & Effect size $f$ & A priori power & Total sample size \\
\hline $\begin{array}{l}\text { D04 cells silenced for NRAS } \\
\text { or CRAF and exposed }\end{array}$ & $F_{(2,6)}=1019.1$ & 0.9971 & 18.5426 & $>99.9 \%$ & 6 \\
to Drug Treatment & & & & & (3 groups)
\end{tabular}

- Bonferroni- corrected planned comparisons; alpha error $=0.0125$ 


\begin{tabular}{lllll} 
Group 1 & Group 2 & Effect size d & A priori power & $\begin{array}{l}\text { Sample } \\
\text { size per group }\end{array}$ \\
\hline Control siRNA Difference & NRAS siRNA Difference & 36.4575 & $99.3 \%^{1}$ & $2^{1}$ \\
\hline Control siRNA Difference & CRAF siRNA Difference & 8.6916 & $99.9 \%$ & 3 \\
\hline
\end{tabular}

- $15 \%$ variance:

- ANOVA: Fixed effects, omnibus, one-way, Bonferroni corrected alpha error $=0.025$

\begin{tabular}{llllll} 
Groups & F test statistic & Partial $\eta^{2}$ & Effect size $f$ & A priori power & Total sample size \\
\hline D04 cells silenced for NRAS & $F_{(2,6)}=72.467$ & 0.9602 & 4.9118 & $99.5 \%$ & 6 \\
or CRAF and exposed & & & & & (3 groups) \\
to Drug Treatment & & & & &
\end{tabular}

- Bonferroni- corrected planned comparisons; alpha error $=0.0125$

\begin{tabular}{lllll} 
Group 1 & Group 2 & Effect size d & A priori power & Sample size per group \\
\hline Control siRNA Difference & NRAS siRNA Difference & 9.7218 & $>99.9 \%$ & 3 \\
\hline Control siRNA Difference & CRAF siRNA Difference & 2.3177 & $80.9 \%$ & 6
\end{tabular}

- $28 \%$ variance:

- ANOVA: Fixed effects, omnibus, one-way, Bonferroni corrected alpha error $=0.025$

\begin{tabular}{llllll} 
Groups & F test statistic & Partial $\eta^{2}$ & Effect size $f$ & A priori power & Total sample size \\
\hline $\begin{array}{l}\text { D04 cells silenced for NRAS } \\
\text { or CRAF and exposed }\end{array}$ & $F_{(2,6)}=20.797$ & 0.8739 & 2.6325 & $99.8 \%$ & 9 \\
to Drug Treatment & & & & & (3 groups) \\
\hline
\end{tabular}

- Bonferroni- corrected planned comparisons; alpha error $=0.0125$

\begin{tabular}{lllll} 
Group 1 & Group 2 & Effect size d & A priori power & Sample size per group \\
\hline Control siRNA Difference & NRAS siRNA Difference & 5.2081 & $89.9 \%$ & 3 \\
\hline Control siRNA Difference & CRAF siRNA Difference & 1.2416 & $82.7 \%$ & 17
\end{tabular}

- $40 \%$ variance:

- ANOVA: Fixed effects, omnibus, one-way, Bonferroni corrected alpha error $=0.025$

\begin{tabular}{llllll} 
Groups & $\mathrm{F}$ test statistic & Partial $\eta^{2}$ & Effect size $\boldsymbol{f}$ & A priori power & Total sample size \\
\hline $\begin{array}{l}\text { D04 cells silenced for NRAS } \\
\text { or CRAF and exposed }\end{array}$ & $F_{(2,6)}=10.191$ & 0.7726 & 1.8432 & $90.8 \%$ & 9 \\
to Drug Treatment & & & & & (3 groups) \\
\hline
\end{tabular}

- Bonferroni- corrected planned comparisons; alpha error $=0.0125$ 


\begin{tabular}{lllll} 
Group 1 & Group 2 & Effect size d & A priori power & Sample size per group \\
\hline Control siRNA Difference & NRAS siRNA Difference & 3.6457 & $89.7 \%$ & 4 \\
\hline Control siRNA Difference & CRAF siRNA Difference & 0.8692 & $81.4 \%$ & 32
\end{tabular}

pERK

- $2 \%$ variance:

- ANOVA: Fixed effects, omnibus, one-way, Bonferroni corrected alpha error $=0.025$

\begin{tabular}{llllll} 
Groups & F test statistic & Partial $\eta^{2}$ & Effect size $f$ & A priori power & Total sample size \\
\hline $\begin{array}{l}\text { D04 cells silenced for NRAS } \\
\text { or CRAF and exposed }\end{array}$ & $F_{(2,6)}=141.13$ & 0.9792 & 6.8613 & $>99.9 \%$ & 6 \\
to Drug Treaps)
\end{tabular}
to Drug Treatment

- Bonferroni- corrected planned comparisons; alpha error $=0.0125$

\begin{tabular}{lllll} 
Group 1 & Group 2 & Effect size d & A priori power & Sample size per group \\
\hline Control siRNA Difference & NRAS siRNA Difference & 13.6467 & $90.2 \%$ & 2 \\
\hline Control siRNA Difference & CRAF siRNA Difference & 8.0474 & $99.9 \%$ & 3
\end{tabular}

- $15 \%$ variance:

- ANOVA: Fixed effects, omnibus, one-way, Bonferroni corrected alpha error $=0.025$

\begin{tabular}{llllll} 
Groups & $\boldsymbol{F}$ test statistic & Partial $\eta^{2}$ & Effect size $\boldsymbol{f}$ & A priori power & Total sample size \\
\hline $\begin{array}{l}\text { D04 cells silenced for NRAS } \\
\text { or CRAF and exposed }\end{array}$ & $F_{(2,6)}=10.036$ & 0.7699 & 1.8292 & $90.3 \%$ & 9 \\
to Drug Treatment & & & & & (3 groups)
\end{tabular}

- Bonferroni- corrected planned comparisons; alpha error $=0.0125$

\begin{tabular}{lllll} 
Group 1 & Group 2 & Effect size $d$ & A priori power & Sample size per group \\
\hline Control siRNA Difference & NRAS siRNA Difference & 3.6391 & $89.3 \%$ & 4 \\
\hline Control siRNA Difference & CRAF siRNA Difference & 2.1460 & $83.7 \%$ & 7
\end{tabular}

- $28 \%$ variance:

- ANOVA: Fixed effects, omnibus, one-way, Bonferroni corrected alpha error $=0.025$

\begin{tabular}{llllll} 
Groups & $F$ test statistic & Partial $\eta^{2}$ & Effect size $f$ & A priori power & Total sample size \\
\hline D04 cells silenced for NRAS & $F_{(2,6)}=2.8802$ & 0.4898 & 0.9798 & $86.4 \%$ & 18 \\
or CRAF and exposed & & & & & (3 groups) \\
to Drug Treatment & & & & \\
\hline
\end{tabular}

- Bonferroni- corrected planned comparisons; alpha error $=0.0125$ 


\begin{tabular}{lllll} 
Group 1 & Group 2 & Effect size d & A priori power & Sample size per group \\
\hline Control siRNA Difference & NRAS siRNA Difference & 1.9495 & $83.1 \%$ & 8 \\
\hline Control siRNA Difference & CRAF siRNA Difference & 1.1496 & $81.4 \%$ & 19
\end{tabular}

- $40 \%$ variance:

- ANOVA: Fixed effects, omnibus, one-way, Bonferroni corrected alpha error $=0.025$

\begin{tabular}{llllll} 
Groups & $F$ test statistic & Partial $\eta^{2}$ & Effect size $f$ & A priori power & Total sample size \\
\hline $\begin{array}{l}\text { D04 cells silenced for NRAS } \\
\text { or CRAF and exposed }\end{array}$ & $F_{(2,6)}=1.4113$ & 0.3199 & 0.6858 & $82.9 \%$ & 30 \\
to Drug Treatment & & & & & (3 groups) \\
\hline
\end{tabular}

- Bonferroni- corrected planned comparisons; alpha error $=0.0125$

\begin{tabular}{lllll} 
Group 1 & Group 2 & Effect size d & A priori power & Sample size per group \\
\hline Control siRNA Difference & NRAS siRNA Difference & 1.3647 & $81.4 \%$ & 14 \\
\hline Control siRNA Difference & CRAF siRNA Difference & 0.8047 & $81.3 \%$ & 37
\end{tabular}

- Based on these power calculations, we will run the experiment four times. Each time, we will quantify band intensity. We will determine the standard deviation of band intensity across the biological replicates and combine this with the effect size from the original study to calculate the number of replicates necessary to reach a power of at least $80 \%$. We will then perform additional replicates, if required, to ensure the experiment has more than $80 \%$ power to detect the original effect.

\section{Protocol 3}

\section{Summary of original data}

- The original data presented is qualitative (images of Western blots). We used Image Studio Lite (LICOR) to perform densitometric analysis of the presented bands. We then performed a priori power calculations with a range of assumed standard deviations to determine the number of replicates to perform.

- Note: band intensity quantified from the image reported in Figure 3A:

\begin{tabular}{lllll} 
Target & Myc-eptitope tagged vector & Drug & Band intensity normalized to IP myc & Assumed N \\
\hline BRAF & CRAF & $885-A$ & 0.01904 & 3 \\
\cline { 3 - 5 } & & DMSO & 0.94756 & 3 \\
\cline { 2 - 5 } & \multirow{2}{*}{ R89L } & $885-A$ & 0.27776 & 3 \\
\cline { 2 - 4 } & DMSO & 0.65427 & 3 \\
\hline
\end{tabular}

\section{Test family}

- Two-way ANOVA ( 2 × 2) on BRAF values followed by Bonferroni corrected comparisons for the following groups:

- Compare the band intensity of BRAF in myc-tagged CRAF ${ }^{W T}$ or CRAF ${ }^{R 89 L}$ in cells treated with or without 885-A 


\section{Power calculations}

- Power calculations were performed using R software version 3.1.2 (R Core Team, 2014) and G*Power (version 3.1.7) (Faul et al., 2007)

- $2 \%$ variance:

- ANOVA: Fixed effects, special, main effects, and interactions; alpha error $=0.05$

\begin{tabular}{|c|c|c|c|c|c|}
\hline Groups & $\begin{array}{l}\text { F test } \\
\text { statistic }\end{array}$ & Partial eta $^{2}$ & Effect size $f$ & A priori power & Total sample size \\
\hline $\begin{array}{l}\text { myc-tagged CRAF }{ }^{W T} \text { or } \\
\text { CRAF R89L in cells with or }_{\text {without } 885-A}\end{array}$ & $\begin{array}{l}F_{(1.8)}= \\
1628.39 \\
\text { (interaction) }\end{array}$ & 0.9951 & 14.267 & $98.7 \%$ & $\begin{array}{l}5 \\
\text { (4 groups) }\end{array}$ \\
\hline
\end{tabular}

- Bonferroni- corrected planned comparisons; alpha error $=0.025$

\begin{tabular}{lllll} 
Group 1 & Group 2 & Effect size d & A priori power & Sample size per group \\
\hline CRAF +885A & CRAF +DMSO & 69.2756 & $99.9 \%$ & 2 \\
\hline R89L +885A & R89L +DMSO & 37.4562 & $99.9 \%$ & 2 \\
\hline
\end{tabular}

- $15 \%$ variance:

- ANOVA: Fixed effects, special, main effects, and interactions; alpha error $=0.05$

\begin{tabular}{llllll} 
Groups & $\begin{array}{l}\mathrm{F} \text { test } \\
\text { statistic }\end{array}$ & Partial eta $^{2}$ & Effect size $\boldsymbol{f}$ & A priori power & Total sample size \\
\hline myc-tagged CRAF $^{\mathrm{WT}}$ or & $\mathrm{F}_{(1.8)}=$ & 0.7835 & 1.9023 & $90.2 \%$ & 7 \\
CRAF $^{\text {R9? }}$ in cells with or & $\begin{array}{l}28.9491 \\
\text { without 885-A }\end{array}$ & & & & (4 groups) \\
interaction & & & &
\end{tabular}

- Bonferroni- corrected planned comparisons; alpha error $=0.025$

\begin{tabular}{lllll} 
Group 1 & Group 2 & Effect size d & A priori power & Sample size per group \\
\hline CRAF +885A & CRAF +DMSO & 9.2367 & $88.1 \%$ & 2 \\
\hline R89L +885A & R89L +DMSO & 4.9941 & $96.0 \%$ & 3 \\
\hline
\end{tabular}

- $28 \%$ variance:

- ANOVA: Fixed effects, special, main effects, and interactions; alpha error $=0.05$

\begin{tabular}{llllll} 
Groups & $\begin{array}{l}\mathrm{F} \text { test } \\
\text { statistic }\end{array}$ & Partial eta $^{2}$ & Effect size $\boldsymbol{f}$ & A priori power & Total sample size \\
\hline $\begin{array}{l}\text { myc-tagged CRAFWT or } \\
\text { CRAF }^{\text {R99 }} \text { in cells with or }\end{array}$ & $\begin{array}{l}\mathrm{F}_{(1.8)}=8.311 \\
\text { interaction }\end{array}$ & .05094 & 1.0191 & $82.5 \%$ & 11 \\
without SB590885 & & & & (4 groups)
\end{tabular}

- Bonferroni- corrected planned comparisons; alpha error $=0.025$ 


\begin{tabular}{lllll} 
Group 1 & Group 2 & Effect size d & A priori power & Sample size per group \\
\hline CRAF +885A & CRAF +DMSO & 4.9482 & $95.8 \%$ & 3 \\
\hline R89L +885A & R89L +DMSO & 2.6754 & $90.1 \%$ & 5 \\
\hline
\end{tabular}

- $40 \%$ variance:

- ANOVA: Fixed effects, special, main effects, and interactions; alpha error $=0.05$

\begin{tabular}{|c|c|c|c|c|c|}
\hline Groups & $\begin{array}{l}\text { F test } \\
\text { statistic }\end{array}$ & Partial eta ${ }^{2}$ & Effect size $f$ & A priori power & Total sample size \\
\hline $\begin{array}{l}\text { myc-tagged CRAF }^{W T} \text { or } \\
\text { CRAF }^{R 89 L} \text { in cells with or } \\
\text { without SB590885 }\end{array}$ & $\begin{array}{l}\mathrm{F}_{(1.8)}=4.071 \\
\text { interaction }\end{array}$ & 0.3372 & 0.7133 & $80.3 \%$ & $\begin{array}{l}18 \\
\text { (4 groups) }\end{array}$ \\
\hline
\end{tabular}

- Bonferroni- corrected planned comparisons; alpha error $=0.025$

\begin{tabular}{lllll} 
Group 1 & Group 2 & Effect size d & A priori power & Sample size per group \\
\hline CRAF +885A & CRAF +DMSO & 3.4638 & $94.0 \%$ & 4 \\
\hline R89L +885A & R89L +DMSO & 1.8728 & $81.2 \%$ & 7
\end{tabular}

- Based on these power calculations, we will run the experiment three times. Each time, we will quantify band intensity. We will determine the standard deviation of band intensity across the biological replicates and combine this with the effect size from the original study to calculate the number of replicates necessary to reach a power of at least $80 \%$. We will then perform additional replicates, if required, to ensure the experiment has more than $80 \%$ power to detect the original effect.

\section{Protocol 4}

Summary of original data

- The original data presented is qualitative (images of Western blots). We used Image Studio Lite (LICOR) to perform densitometric analysis of the presented bands. We then performed a priori power calculations with a range of assumed standard deviations to determine the number of replicates to perform.

- Note: band intensity quantified from the image reported in Figure 3B:

\begin{tabular}{lllll} 
Target & Myc-eptitope tagged vector & Drug & Band intensity normalized to IP myc & Assumed N \\
\hline CRAF & BRAF & $885-A$ & 0.0320 & 3 \\
\cline { 3 - 5 } & & DMSO & 0.6015 & 3 \\
\cline { 2 - 5 } & \multirow{2}{*}{ R188L } & $885-A$ & 0.0164 & 3 \\
\cline { 2 - 5 } & DMSO & 0.1012 & 3
\end{tabular}

\section{Test family}

- Two-way ANOVA $(2 \times 2)$ on CRAF values followed by Bonferroni corrected comparisons for the following groups:

- Compare the band intensity of BRAF in myc-tagged BRAF ${ }^{\mathrm{WT}}$ or $\mathrm{BRAF}^{\mathrm{R} 188 \mathrm{~L}}$ in cells treated with or without 885-A 


\section{Power calculations}

- Power calculations were performed using R software version 3.1.2 ( $R$ Core Team, 2014) and G*Power (version 3.1.7) (Faul et al., 2007)

- $2 \%$ variance:

- ANOVA: Fixed effects, special, main effects, and interactions; alpha error $=0.05$

\begin{tabular}{llllll} 
Groups & $\begin{array}{l}\mathrm{F} \text { test } \\
\text { statistic }\end{array}$ & Partial eta $^{2}$ & Effect size $f$ & A priori power & Total sample size \\
\hline $\begin{array}{l}\text { myc-tagged BRAFWT or } \\
\text { BRAF }^{\text {R188L }} \text { in cells with or }\end{array}$ & $\begin{array}{l}\mathrm{F}_{(1.8)}= \\
\begin{array}{l}4718.4 \\
\text { without 885-A }\end{array}\end{array}$ & 0.998 & 24.28 & $99.9 \%$ & 5 \\
\hline
\end{tabular}

- Bonferroni- corrected planned comparisons; alpha error $=0.025$

\begin{tabular}{lllll} 
Group 1 & Group 2 & Effect size d & A priori power & Sample size per group \\
\hline BRAF +885A & BRAF +DMSO & 66.85 & $99.9 \%$ & 2 \\
\hline R188L +885A & R188L +DMSO & 58.51 & $99.9 \%$ & 2
\end{tabular}

- $15 \%$ variance:

- ANOVA: Fixed effects, special, main effects, and interactions; alpha error $=0.05$

\begin{tabular}{|c|c|c|c|c|c|}
\hline Groups & $\begin{array}{l}F \text { test } \\
\text { statistic }\end{array}$ & Partial eta ${ }^{2}$ & Effect size $f$ & A priori power & Total sample size \\
\hline $\begin{array}{l}\text { myc-tagged BRAF }{ }^{W T} \text { or } \\
\text { BRAF }^{R T 8} \text { in }_{\text {in }} \text { cells with or } \\
\text { without 885-A }\end{array}$ & $\begin{array}{l}\mathrm{F}_{(1.8)}= \\
83.88 \\
\text { interaction }\end{array}$ & 0.913 & 3.238 & $95.6 \%$ & 6 \\
\hline
\end{tabular}

- Bonferroni- corrected planned comparisons; alpha error $=0.025$

\begin{tabular}{lllll} 
Group 1 & Group 2 & Effect size d & A priori power & Sample size per group \\
\hline BRAF +885A & BRAF +DMSO & 8.914 & $86.3 \%$ & 2 \\
\hline R188L +885A & R188L +DMSO & 7.801 & $99.9 \%$ & 3 \\
\hline
\end{tabular}

- $28 \%$ variance:

- ANOVA: Fixed effects, special, main effects, and interactions; alpha error $=0.05$

\begin{tabular}{llllll} 
Groups & $\begin{array}{l}\mathrm{F} \text { test } \\
\text { statistic }\end{array}$ & Partial eta $^{2}$ & Effect size $\boldsymbol{f}$ & A priori power & Total sample size \\
\hline $\begin{array}{l}\text { myc-tagged BRAFWT or } \\
\text { BRAF }^{\text {R188L }} \text { in cells with or } \\
\text { without 885-A }\end{array}$ & $\begin{array}{l}\mathrm{F}_{(1.8)}=24.07 \\
\text { interaction }\end{array}$ & 0.750 & 1.734 & $85.0 \%$ & 7 \\
\hline
\end{tabular}

- Bonferroni- corrected planned comparisons; alpha error $=0.025$ 


\begin{tabular}{lllll} 
Group 1 & Group 2 & Effect size d & A priori power & Sample size per group \\
\hline BRAF +885A & BRAF +DMSO & 4.775 & $94.5 \%$ & 3 \\
\hline R188L +885A & R188L +DMSO & 4.179 & $87.8 \%$ & 3 \\
\hline
\end{tabular}

- $40 \%$ variance:

- ANOVA: Fixed effects, special, main effects, and interactions; alpha error $=0.05$

\begin{tabular}{|c|c|c|c|c|c|}
\hline Groups & $\begin{array}{l}\text { F test } \\
\text { statistic }\end{array}$ & Partial eta ${ }^{2}$ & Effect size $f$ & A priori power & Total sample size \\
\hline $\begin{array}{l}\text { myc-tagged BRAF }{ }^{W T} \text { or } \\
\text { BRAF }^{R / 88 L} \text { in cells with or } \\
\text { without 885-A }\end{array}$ & $\begin{array}{l}\mathrm{F}_{(1.8)}=11.79 \\
\text { interaction }\end{array}$ & 0.596 & 1.214 & $82.7 \%$ & 9 \\
\hline
\end{tabular}

- Bonferroni- corrected planned comparisons; alpha error $=0.025$

\begin{tabular}{lllll} 
Group 1 & Group 2 & Effect size d & A priori power & Sample size per group \\
\hline BRAF +885A & BRAF +DMSO & 3.343 & $92.3 \%$ & 4 \\
\hline R188L +885A & R188L +DMSO & 2.925 & $83.9 \%$ & 4
\end{tabular}

- Based on these power calculations, we will run the experiment three times. Each time, we will quantify band intensity. We will determine the standard deviation of band intensity across the biological replicates and combine this with the effect size from the original study to calculate the number of replicates necessary to reach a power of at least $80 \%$. We will then perform additional replicates, if required, to ensure the experiment has more than $80 \%$ power to detect the original effect.

\section{Protocol 5}

Summary of original data

- The original data presented is qualitative (images of Western blots). We used Image Studio Lite (LICOR) to perform densitometric analysis of the presented bands. We then performed a priori power calculations with a range of assumed standard deviations to determine the number of replicates to perform.

- Note: band intensity quantified from the image reported in Figure 4D

- The band intensities for two groups were beyond the dynamic range for intensity calculation:

- IP myc-tagged BRAF in cells transfected with the BRAF mutant (D594A): In this case, we used the value for band intensity of IP myc-tagged BRAF in cells transfected with wild type BRAF as an estimate. Since the band for wild type BRAF transfected cells was less intense, this underestimates the effect size, so we are likely overestimating the sample size required.

\begin{tabular}{llll} 
Target & Vector & $\begin{array}{l}\text { Band intensity normalized } \\
\text { to IP myc }\end{array}$ & Assumed N \\
\hline IP CRAF & BRAF & 0.164 & 3 \\
\cline { 2 - 4 } & D594A & 0.739 & 3
\end{tabular}


Test family

- Unpaired two-tailed Welch's t-test, alpha error $=0.05$.

\section{Power calculations}

- Power calculations were performed using R software version 3.2.2 (R Core Team, 2014)

\begin{tabular}{llllll} 
Group 1 & Group 2 & $\begin{array}{l}\text { Variance } \\
\text { estimate }\end{array}$ & $\begin{array}{l}\text { Effect size } \\
\left(\text { (llass' }^{1}\right)^{1}\end{array}$ & A priori power & $\begin{array}{l}\text { Sample size } \\
\text { per group }\end{array}$ \\
\hline BRAFWT $^{\text {B }}$ & BRAF $^{\text {D594A }}$ & $2 \%$ & 175.30 & $>99.9 \%$ & 2 \\
\cline { 2 - 5 } & & 23.374 & $89.9 \%$ & 2 \\
\cline { 2 - 5 } & $28 \%$ & 12.522 & $93.3 \%$ & 3 \\
\hline
\end{tabular}

${ }^{1}$ The BRAF group SD was used as the divisor.

- Based on these power calculations, we will run the experiment three times. Each time, we will quantify band intensity. We will determine the standard deviation of band intensity across the biological replicates and combine this with the effect size from the original study to calculate the number of replicates necessary to reach a power of at least $80 \%$. We will then perform additional replicates, if required, to ensure the experiment has more than $80 \%$ power to detect the original effect.

\section{Acknowledgements}

The Reproducibility Project: Cancer Biology core team would like to thank the original authors, in particular Sonja Heidorn and Richard Marais, for generously sharing critical information as well as reagents to ensure the fidelity and quality of this replication attempt. We thank Courtney Soderberg at the Center for Open Science for assistance with statistical analyses. We also thank the following companies for generously d9onating reagents to the Reproducibility Project: Cancer Biology; American Type and Tissue Collection (ATCC), Applied Biological Materials, BioLegend, Charles River Laboratories, Corning Incorporated, DDC Medical, EMD Millipore, Harlan Laboratories, LI-COR Biosciences, Mirus Bio, Novus Biologicals, Sigma-Aldrich, and System Biosciences (SBI).

\section{Additional information}

Group author details

Reproducibility Project: Cancer Biology

Elizabeth lorns: Science Exchange, Palo Alto, United States; William Gunn: Mendeley, London, United Kingdom; Fraser Tan: Science Exchange, Palo Alto, United States; Joelle Lomax: Science Exchange, Palo Alto, United States; Stephen R Williams: Science Exchange, Palo Alto, United States; Nicole Perfito: Science Exchange, Palo Alto, United States; Timothy Errington: Center for Open Science, Charlottesville, United States

Competing interests

AB, MA: Shakti BioResearch LLC, is a Science Exchange lab. RP:CB: El, FT, JL, and NP are employed by and hold shares in Science Exchange Inc. The other authors declare that no competing interests exist. 
Funding

Funder

Author

Laura and John Arnold

Nicole Perfito

Foundation

The funders had no role in study design, data collection and interpretation, or the decision to submit the work for publication.

Author contributions

$A B, M A, H M$, Drafting or revising the article; RP:CB, NP, Conception and design, Drafting or revising the article

\section{References}

Aplin AE, Kaplan FM, Shao Y. 2011. Mechanisms of resistance to RAF inhibitors in melanoma. Journal of Investigative Dermatology 131:1817-1820. doi: 10.1038/jid.2011.147

Carnahan J, Beltran PJ, Babij C, Le Q, Rose MJ, Vonderfecht S, Kim JL, Smith AL, Nagapudi K, Broome MA, Fernando M, Kha H, Belmontes B, Radinsky R, Kendall R, Burgess TL. 2010. Selective and potent raf inhibitors paradoxically stimulate normal cell proliferation and tumor growth. Molecular Cancer Therapeutics 9:23992410. doi: 10.1158/1535-7163.MCT-10-0181

Dumaz N, Hayward R, Martin J, Ogilvie L, Hedley D, Curtin JA, Bastian BC, Springer C, Marais R. 2006. In melanoma, RAS mutations are accompanied by switching signaling from BRAF to CRAF and disrupted cyclic AMP signaling. Cancer Research 66:9483-9491. doi: 10.1158/0008-5472.CAN-05-4227

Errington TM, lorns E, Gunn W, Tan FE, Lomax J, Nosek BA. 2014. An open investigation of the reproducibility of cancer biology research. eLife 3. doi: 10.7554/eLife.04333

Faul F, Erdfelder E, Lang A-G, Buchner A. 2007. G*power 3: a flexible statistical power analysis program for the social, behavioral, and biomedical sciences. Behavior Research Methods 39:175-191. doi: 10.3758/BF03193146

Hatzivassiliou G, Song K, Yen I, Brandhuber BJ, Anderson DJ, Alvarado R, Ludlam MJC, Stokoe D, Gloor SL, Vigers G, Morales T, Aliagas I, Liu B, Sideris S, Hoeflich KP, Jaiswal BS, Seshagiri S, Koeppen H, Belvin M, Friedman LS, Malek S. 2010. RAF inhibitors prime wild-type RAF to activate the MAPK pathway and enhance growth. Nature 464:431-435. doi: 10.1038/nature08833

Hall-Jackson CA, Eyers PA, Cohen P, Goedert M, Tom Boyle F, Hewitt N, Plant H, Hedge P. 1999a. Paradoxical activation of raf by a novel raf inhibitor. Chemistry \& Biology 6:559-568. doi: 10.1016/S1074-5521(99)80088-X

Hall-Jackson CA, Goedert M, Hedge P, Cohen P. 1999b. Effect of SB 203580 on the activity of c-raf in vitro and in vivo. Oncogene 18:2047-2054. doi: 10.1038/sj.onc.1202603

Heidorn SJ, Milagre C, Whittaker S, Nourry A, Niculescu-Duvas I, Dhomen N, Hussain J, Reis-Filho JS, Springer CJ, Pritchard C, Marais R. 2010. Kinase-dead BRAF and oncogenic RAS cooperate to drive tumor progression through CRAF. Cell 140:209-221. doi: 10.1016/j.cell.2009.12.040

Joseph EW, Pratilas CA, Poulikakos PI, Tadi M, Wang W, Taylor BS, Halilovic E, Persaud Y, Xing F, Viale A, Tsai J, Chapman PB, Bollag G, Solit DB, Rosen N. 2010. The RAF inhibitor PLX4032 inhibits ERK signaling and tumor cell proliferation in a V600E BRAF-selective manner. Proceedings of the National Academy of Sciences of the United States of America 107:14903-14908. doi: 10.1073/pnas.1008990107

Kaplan FM, Shao Y, Mayberry MM, Aplin AE. 2011. Hyperactivation of MEK-ERK1/2 signaling and resistance to apoptosis induced by the oncogenic b-RAF inhibitor, PLX4720, in mutant n-RAS melanoma cells. Oncogene 30 : 366-371. doi: 10.1038/onc.2010.408

Lakens D. 2013. Calculating and reporting effect sizes to facilitate cumulative science: a practical primer for ttests and ANOVAs. Frontiers in Psychology 4:863. doi: 10.3389/fpsyg.2013.00863

Lee JT, Li L, Brafford PA, van den Eijnden M, Halloran MB, Sproesser K, Haass NK, Smalley KSM, Tsai J, Bollag G, Herlyn M. 2010. PLX4032, a potent inhibitor of the b-raf V600E oncogene, selectively inhibits V600E-positive melanomas. Pigment Cell \& Melanoma Research 23:820-827. doi: 10.1111/j.1755-148X.2010.00763.x

Lidsky M, Antoun G, Speicher P, Adams B, Turley R, Augustine C, Tyler D, Ali-Osman F. 2014. Mitogen-activated protein kinase (mAPK) hyperactivation and enhanced NRAS expression drive acquired vemurafenib resistance in V600E BRAF melanoma cells. Journal of Biological Chemistry 289:27714-27726. doi: 10.1074/jbc.M113. 532432

Nazarian R, Shi H, Wang Q, Kong X, Koya RC, Lee H, Chen Z, Lee M-K, Attar N, Sazegar H, Chodon T, Nelson SF, McArthur G, Sosman JA, Ribas A, Lo RS. 2010. Melanomas acquire resistance to b-RAF(V600E) inhibition by RTK or n-RAS upregulation. Nature 468:973-977. doi: 10.1038/nature09626

Packer LM, Rana S, Hayward R, O'Hare T, Eide CA, Rebocho A, Heidorn S, Zabriskie MS, Niculescu-Duvaz I, Druker BJ, Springer C, Marais R. 2011. Nilotinib and MEK inhibitors induce synthetic lethality through paradoxical activation of RAF in drug-resistant chronic myeloid leukemia. Cancer Cell 20:715-727. doi: 10. 1016/j.ccr.2011.11.004

Poulikakos PI, Zhang C, Bollag G, Shokat KM, Rosen N. 2010. RAF inhibitors transactivate RAF dimers and ERK signalling in cells with wild-type BRAF. Nature 464:427-430. doi: 10.1038/nature08902

R Core Team. 2014. R: a language and environment for statistical computing. From: http://www.R-project.org/. 
Rebocho AP, Marais R. 2013. ARAF acts as a scaffold to stabilize BRAF:CRAF heterodimers. Oncogene 32:32073212. doi: 10.1038/onc.2012.330

Solit DB, Rosen N. 2014. Towards a unified model of RAF inhibitor resistance. Cancer Discovery 4:27-30. doi: 10. 1158/2159-8290.CD-13-0961

Su F, Viros A, Milagre C, Trunzer K, Bollag G, Spleiss O, Reis-Filho JS, Kong X, Koya RC, Flaherty KT, Chapman PB, Kim MJ, Hayward R, Martin M, Yang H, Wang Q, Hilton H, Hang JS, Noe J, Lambros M, Geyer F, Dhomen N, Niculescu-Duvaz I, Zambon A, Niculescu-Duvaz D, Preece N, Robert L, Otte NJ, Mok S, Kee D, Ma Y, Zhang C, Habets G, Burton EA, Wong B, Nguyen H, Kockx M, Andries L, Lestini B, Nolop KB, Lee RJ, Joe AK, Troy JL, Gonzalez R, Hutson TE, Puzanov I, Chmielowski B, Springer CJ, McArthur GA, Sosman JA, Lo RS, Ribas A, Marais R, Milagre C, Trunzer K. 2012. RAS mutations in cutaneous squamous-cell carcinomas in patients treated with BRAF inhibitors. New England Journal of Medicine 366:207-215. doi: 10.1056/NEJMoa1105358

Team RC. 2015. R: A Language and Environment for Statistical Computing. Vienna, Austria: R Foundation for Statistical Computing.

Weber CK, Slupsky JR, Kalmes HA, Rapp UR. 2001. Active ras induces heterodimerization of cRaf and BRaf. Cancer Research 61:3595-3598. papers3://publication/uuid/2540E5B8-390E-48E2-906E-D115147EA81F. 